\title{
Comparison of the Reinforcing Properties of Nicotine and Cigarette Smoke Extract in Rats
}

\author{
Matthew R Costello*,', Daisy D Reynaga', Celina Y Mojica', Nurulain T Zaveri', James D Belluzzi' and \\ Frances M Leslie'
}

'Department of Pharmacology, School of Medicine, University of California, Irvine, CA, USA; ${ }^{2}$ Astraea Therapeutics,

Mountain View, CA, USA

\begin{abstract}
Tobacco dependence is difficult to treat, with the vast majority of those who try to quit relapsing within the first year. Improvements in smoking cessation therapies may be achieved by improving current preclinical research methods. However, most experimental tests in animals use nicotine alone, ignoring the 8000 other constituents found in tobacco smoke. To improve on this model, we have used selfadministration to test the reinforcing properties of aqueous cigarette smoke extract (CSE) in rats, made by bubbling cigarette smoke through a saline solution. CSE is more potent than nicotine alone in both the acquisition and maintenance of self-administration, but did not exhibit higher progressive ratio responding. Mecamylamine and varenicline had similar potencies to block nicotine and CSE selfadministration, indicating the involvement of nicotinic receptors in CSE reinforcement. Following extinction of responding, reinstatement was triggered by exposing animals to a pharmacological stressor, yohimbine $(2.5 \mathrm{mg} / \mathrm{kg}$, i.p.), alone and in combination with cues. Animals that self-administered CSE were significantly more sensitive to stress-induced reinstatement than those that self-administered nicotine. Ligand binding autoradiography studies showed nicotine and CSE to have similar affinities for different nicotinic receptor types. CSE significantly reduced MAO-A and MAO-B activities in vitro, whereas nicotine did not. Although CSE inhibition of MAO-A activity in vitro was found to be partially irreversible, irreversible inhibition was not observed in vivo. These experiments show that CSE is an effective reinforcer acting via nicotinic receptors. Furthermore, it better models MAO inhibition and is more sensitive to stress-induced reinstatement than nicotine alone, which is a potent trigger for relapse in smokers.

Neuropsychopharmacology (2014) 39, I843-|85I; doi:10.1 1038/npp.2014.31; published online 12 March 2014
\end{abstract}

Keywords: tobacco dependence; $\alpha 3 \beta 4$ nAChR antagonist; self-administration; reinstatement; stress; monoamine oxidase

\section{INTRODUCTION}

Nearly one in five Americans are smokers, most of whom express a desire to quit (CDC, 2008). This yields a population of $\sim 35$ million people within the United States who are current smokers who contemplate cessation; yet, the success rates of tobacco dependence treatments are extremely low. In clinical trials, up to $90 \%$ of smokers relapse within the first year of treatment; even with the most effective pharmacological treatment, varenicline, only $23 \%$ of people stay smokefree for a full year (Jorenby et al, 2006).

Development of effective smoking cessation therapies may be hampered by an oversimplified preclinical model. Nicotine is widely used as a proxy for tobacco in animal studies (eg, Coe et al, 2005; Donny et al, 1995), although there are over 8000 compounds in cigarette smoke (Centers for Disease Control and Prevention, 2010). Increasing evidence suggests that nicotine is not equivalent to tobacco. Smokers will not

*Correspondence: Dr MR Costello, Department of Pharmacology, 367 Med Surge II, University of California, Irvine, CA 92697, USA,

Tel: + I 949824765 I, E-mail: mcostell@gmail.com

Received 30 September 2013; revised 3 January 2014; accepted 23 January 20 I4; accepted article preview online II February 2014 reliably self-administer nicotine (Dar and Frenk, 2004), and denicotinized cigarettes reduce craving as effectively as standard cigarettes (King et al, 2009). Denicotinized cigarette smoking also releases dopamine, although in different brain regions than regular cigarettes (Brody et al, 2010; Domino et al, 2013). Monoamine oxidase (MAO), an enzyme that degrades serotonin, dopamine, and norepinephrine, is chronically inhibited in smokers (Fowler et al, 1996a,b), yet nicotine has no effect on its activity (Oreland et al, 1981). Furthermore, nicotine replacement therapy is not highly effective, with only $17 \%$ of treated smokers remaining abstinent after a year (Reus and Smith, 2008).

Preclinical studies have identified a number of behaviorally active nonnicotine tobacco constituents. We and others have found that treating animals with MAO inhibitors increases nicotine self-administration in adults (Guillem et al, 2005; Villégier et al, 2007). Tobacco alkaloids, chemically related to nicotine, also increase nicotine self-administration and increase striatal dopamine release in rats (Clemens et al, 2009; Khalki et al, 2013). Our group has also shown that acetaldehyde dramatically enhances nicotine self-administration in adolescent, but not adult, animals (Belluzzi et al, 2005). However, these studies all attempt to measure the effects of a small set of compounds mixed with nicotine and 
thus still exclude many compounds found in tobacco smoke and interactions between known constituents.

Extracts of tobacco, and its smoke, provide a way to study the collective contribution of many tobacco constituents. These have been used for many years in cancer research (see, eg, Liu et al, 2007; Sydnor et al, 1972), and yet they have been largely ignored until recently in behavioral testing. Harris et al (2011) compared nicotine with an extract of smokeless tobacco, and found that nicotine became aversive at high doses whereas tobacco extract did not. Particulate matter, derived from an ethanol extract of tobacco, produces similar effects to nicotine on locomotor activity (Brennan et al, 2013). Smoke extract, which contains many combustion products not present in tobacco leaf (Bates et al, 1999; Seeman et al, 2002), has been shown to have in vitro effects on dopamine neurons that are distinct from those of tobacco extract (Marti et al, 2011) and on serotonin neurons that are distinct from those of nicotine (Touiki et al, 2007). However, to date, there have been no studies of the behaviorally reinforcing effects of tobacco smoke extracts.

In the present study, we have used self-administration to examine the reinforcing effects of aqueous cigarette smoke extract (CSE), prepared by bubbling smoke from commercial cigarettes through saline solution. We hypothesized that CSE would be more reinforcing than pure nicotine in several phases of drug-taking behavior. Furthermore, we hypothesized that CSE would act through both nicotinic receptor (nAChR)- and non-nAChR-mediated pathways, such as MAO inhibition, and that nAChR antagonists would have differential effects on the self-administration of nicotine and CSE.

\section{MATERIALS AND METHODS}

\section{Drugs}

Nicotine hydrogen tartrate (Sigma, St Louis, MO) was dissolved in sterile saline and adjusted to $\mathrm{pH}$ 7.2-7.4. All nicotine doses were calculated as free base. CSE was created by bubbling the smoke from commercial cigarettes (Camel unfiltered, RJ Reynolds) through sterile saline, using a method adapted from Bernhard et al (2004). Eight cigarettes were smoked through $35 \mathrm{ml}$ of room temperature saline solution ( $35 \mathrm{ml}$ puffs over $2 \mathrm{~s}$, repeated every $30 \mathrm{~s} ; \sim 8 \mathrm{~cm}$ depth of saline) and the final solution was adjusted to $\mathrm{pH}$ 7.2-7.4. The CSE solution was prepared fresh each day immediately before experimental testing in order to minimize differences resulting from differential stability of each of the constituents. All CSE doses were defined by the nicotine content in the solution. Samples of the CSE preparations were sent to an outside facility to analyze nicotine content (UCSF Clinical Pharmacology Laboratory) and the content of every solution was confirmed using a test strip (NicCheck I, Mossman Associates, Milford, MA). Mecamylamine $\mathrm{HCl}$ and yohimbine $\mathrm{HCl}$ (Tocris Bioscience, Bristol, UK), propofol (Abbott Laboratories, Chicago, IL), varenicline $\mathrm{HCl}$ (National Institute on Drug Abuse), or varenicline tartrate (Sigma-Aldrich) were dissolved in sterile saline; AT-1001, an $\alpha 3 \beta 4$ selective nAChR antagonist (Toll et al, 2012), was dissolved in 97\% hydroxypropylcellulose ( $0.5 \%$ concentration in water), $2 \%$ DMSO, and $1 \% 0.1 \mathrm{M}$
HCl. For neurochemical studies, cytisine (Sigma), cobratoxin (Fisher Scientific, Waltham, MA), ${ }^{125} \mathrm{I}$-epibatidine, ${ }^{125} \mathrm{I}-\alpha-$ bungarotoxin, ${ }^{14} \mathrm{C}$-phenylethylamine, and ${ }^{14} \mathrm{C}$-serotonin (Perkin-Elmer, Waltham, MA) were used.

\section{Animals}

Adult male Sprague-Dawley rats (300-325 g) were obtained from Charles River Labs (Hollister, CA) and housed in an AALAC-accredited vivarium on a 12-h light/dark cycle $(1900$ to $0700 \mathrm{~h})$. All procedures were in compliance with $\mathrm{NIH}$ guidelines and were approved by the Institutional Animal Care and Use Committee of the University of California, Irvine. Animals were handled daily before testing. Behavioral tests were conducted 7 days per week. During food training, animals had dietary restriction to maintain $85 \%$ of their free-feeding body weight.

\section{Behavioral Studies}

Apparatus. Animals were tested in a plexiglass operant chamber (Med Associates, St Albans, VT), equipped with nose pokes for acquisition studies and levers for all others. Responses at the reinforced (R) hole/lever resulted in illumination of the cue light over that hole/lever and activation of an externally mounted syringe pump that infused drug. The cue light remained on during the infusion (5.6 s yielding $100 \mu \mathrm{l}$ of solution), then both the cue light and house light were turned off for the timeout period. Responses in the non-reinforced (NR) hole were recorded but had no consequence.

Surgery. Animals were anesthetized with equithesin $(0.0035 \mathrm{ml} / \mathrm{g}$ body weight $)$ and implanted with indwelling jugular vein catheters (Belluzi et al, 2005). During the 3-day recovery period, cannulas were flushed daily with heparinized saline solution to maintain catheter patency. The day before initiation of self-administration, and at intervals thereafter, catheter patency was verified for rapid anesthesia by infusing propofol ( $5 \mathrm{mg} / \mathrm{kg}$, i.v.). Patency was tested after each phase of the self-administration studies (eg, acquisition, antagonist tests, dose-response tests; not more frequently than every 5 days) and only animals showing rapid anesthesia were included in analyses.

Nose poke. At 3 days after catheterization surgery, animals began testing in $1 \mathrm{~h}$ sessions without prior food training for acquisition of self-administration. On days 1-7, testing was done at a FR1TO20 (fixed-ratio 1, $20 \mathrm{~s}$ timeout) schedule, on days $8-10$ at FR2TO20, and on days $11-15$ at FR5TO20. Following a preliminary dose-finding study, animals received either CSE or nicotine at $3.75 \mu \mathrm{g} / \mathrm{kg} /$ infusion nicotine content. Data were analyzed by three-way ANOVA $(\mathrm{R} / \mathrm{NR} \times$ day $\times$ dose, repeated measure on R/NR and day). Significant main effects were further investigated using paired (R/NR and day) and unpaired (dose) $t$-tests.

Lever press. Animals were initially trained in $30 \mathrm{~min}$ sessions to lever press for food pellets $(45 \mathrm{mg}$ rodent purified diet; Bio-Serv, Frenchtown, NJ), first at an FR1TO1 schedule, and increasing progressively to FR1TO10, 
FR2TO20, and FR5TO20 upon earning 50 pellets. Animals were then implanted with catheters and began $1 \mathrm{~h}$ drug selfadministration sessions of nicotine or CSE $(15 \mu \mathrm{g} / \mathrm{kg} /$ infusion nicotine content) at FR5TO20. Upon reaching stable responding $(\mathrm{R}= \pm 20 \%$ over 3 days; $\mathrm{R}>=2 \times \mathrm{NR}$; $\mathrm{R}>=6$ ) and after at least 10 days of self-administration, experimental testing began.

Dose response. Nicotine and CSE doses were reduced for a 3 -day test period in a counterbalanced design to $0,3.75$, or $7.5 \mu \mathrm{g} / \mathrm{kg} /$ infusion nicotine content. Animals were returned to $15 \mu \mathrm{g} / \mathrm{kg} /$ infusion nicotine content before the next test dose. Data from day 3 at each dose were analyzed by two-way ANOVA with dose and drug as between-subject factors. Significant main effects were further analyzed with unpaired $t$-tests.

Progressive ratio, extinction, and reinstatement. Once stable responding at FR5TO20 for nicotine or CSE $(15 \mu \mathrm{g} /$ $\mathrm{kg}$ /infusion nicotine content) was achieved, a separate group of animals was tested for 5 days on a progressive ratio (PR) schedule (Donny et al, 1999). The number of responses required to earn an infusion was based on the following schedule: $3,6,10,15,20,25,32,40,50,62,77$, and 95 . Following PR tests, animals were returned to the FR5TO20 schedule for at least 3 days until reaching stable responding criteria. Reinforced behavior was then extinguished by removal of drug and associated cues until responding was reduced to $\leqslant 20 \%$ of the last day of drug self-administration and for a minimum of 5 days. Reinstatement testing then began using three conditions in a randomized order that have been shown previously to reinstate responding for nicotine (Feltenstein et al, 2012): Cues only, Stress only (yohimbine $(2.5 \mathrm{mg} / \mathrm{kg}$, i.p., a pharmacological stressor (See and Waters, 2010)) $30 \mathrm{~min}$ before testing), and Cues + Stress. Between reinstatement tests animals were returned to extinction conditions for a minimum of 2 days or until extinction criteria were met. PR and extinction data were analyzed by two-way ANOVA on drug $\times$ day with repeated measures on day. Reinstatement data were analyzed by drug $\times$ reinstatement condition with repeated measures on reinstatement condition. Significant main effects were analyzed further with appropriate post hoc tests.

$n A C h R$ antagonist blockade of stable responding. Separate groups of animals were treated with mecamylamine $(0,0.5,1$, and $2 \mathrm{mg} / \mathrm{kg}$ at $15 \mathrm{~min}$ before test, s.c.), AT- 1001 $(0,0.75,1.5$, and $3 \mathrm{mg} / \mathrm{kg}$ at $10 \mathrm{~min}$ before test, s.c.), or varenicline $(0.3,1$, and $3 \mathrm{mg} / \mathrm{kg}$ at $15 \mathrm{~min}$ before test, s.c.) in a within-subject latin-square design (Toll et al, 2012). Catheter patency was verified by administering propofol and tested for rapid anesthesia the day before or directly after each antagonist test. Mecamylamine and varenecline were tested against both nicotine and CSE, with data analyzed as a percentage of baseline responding and analyzed by two-way ANOVA with dose and drug as between-subject factors. Significant main effects were further analyzed with paired $t$-tests. As we have recently published data on AT-1001 inhibition of nicotine selfadministration (Toll et al, 2012), this drug was initially tested only against CSE. Upon completion of all antagonist doses, animals were switched to nicotine self-administration and the inhibitory effects of AT-1001 $(3 \mathrm{mg} / \mathrm{kg})$ were tested.

\section{Neurochemical Studies}

$n A C h R$ ligand binding autoradiography. To compare the affinities of nicotine and CSE for various nAChR types, brains were sectioned on a cryostat, mounted to slides, and processed for binding under conditions that selectively label different nAChR types (Perry et al, 2002; Ospina et al, 1998). Treated slides were placed in light-tight cassettes with ${ }^{14} \mathrm{C}$ standards of known radioactivity and exposed to Kodak BioMax MR film.

Autoradiograms were quantified using the MCID computer-based imaging system (Imaging Research). Using the standard curve, radioactivity was measured in regions of interest; ventral posterior thalamic nucleus for $\alpha 4 \beta 2$, medial habenula for $\alpha 3 \beta 4$, superior colliculus for $\alpha 3 \beta 2$, and dentate gyrus for $\alpha 7$. Specific binding was calculated by subtracting the radioactivity in the presence of excess inhibitor from total binding values. Data were analyzed using nonlinear regression with Prism (GraphPad, La Jolla, CA) to determine $\mathrm{Ki}$ values for CSE and nicotine at each nAChR type.

\section{MAO activity}

In vitro. MAO activity was assessed based on Hauptman and Shih (2001). A total of $100 \mu$ l aliquots of a rat brain mitochondrial homogenate were preincubated with CSE or nicotine $\left(0-100 \mu \mathrm{M}\right.$ nicotine content) for $7 \mathrm{~min}$ at $37^{\circ} \mathrm{C} .{ }^{14} \mathrm{C}$ serotonin for MAO-A or ${ }^{14} \mathrm{C}$-phenylethylamine for MAO-B activity were then added with unlabeled compound to achieve a final concentration of $1 \mathrm{mM}$ within the assay mixture. Blanks omitted brain homogenate. After $20 \mathrm{~min}$, the reaction was terminated by cooling on ice and adding $100 \mu \mathrm{l}$ of $6 \mathrm{~N} \mathrm{HCl}$. Products were extracted with benzene/ethyl acetate for ${ }^{14} \mathrm{C}$-serotonin or toluene for ${ }^{14} \mathrm{C}$-phenylethylamine and centrifuged for $7 \mathrm{~min}$ at $1400 \times \mathrm{g}$. For scintillation counting, $4 \mathrm{ml}$ of the organic layer was removed.

To test whether enzyme inhibition was reversible, $100 \mu \mathrm{l}$ of brain homogenate was incubated with either 0 or $100 \mu \mathrm{M}$ CSE as above, centrifuged at $12000 \times g$ for $8 \mathrm{~min}$ at $4{ }^{\circ} \mathrm{C}$, and resuspended in buffer twice. MAO-A and -B activity was then assayed as above. CSE inhibition was calculated as percent of control.

Ex vivo. Rats implanted with a jugular vein catheter were given 15 preprogrammed infusions spaced evenly throughout the $1 \mathrm{~h}$ session of either CSE (15 $\mu \mathrm{g} / \mathrm{kg} / \mathrm{infusion})$, nicotine $(15 \mu \mathrm{g} / \mathrm{kg} /$ infusion $)$, or saline (100 $\mu \mathrm{l} /$ infusion). Following treatment, rats were killed, brains collected and homogenized, the membranes washed twice, and then assayed for MAO-A and -B activities as above.

\section{RESULTS}

\section{Acquisition Study}

A nose poke procedure was used that allows for rapid acquisition of nicotine self-administration behavior. CSE supported acquisition of self-administration behavior at the $3.75 \mu \mathrm{g} / \mathrm{kg} /$ infusion nicotine content dose, whereas the 

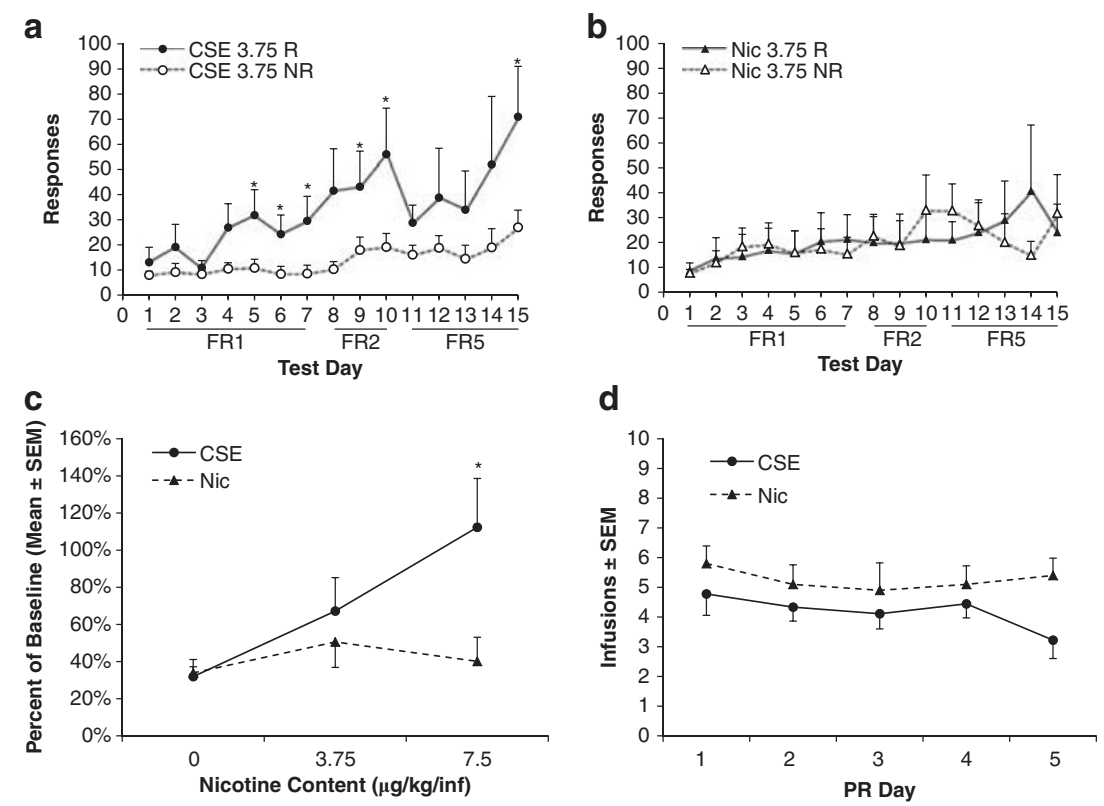

Figure I Cigarette smoke extract (CSE) is more potent than pure nicotine but equally reinforcing. (a, b) CSE supports acquisition of intravenous selfadministration at lower doses than nicotine alone. CSE with a nicotine content of $3.75 \mu \mathrm{g} / \mathrm{kg} / \mathrm{inj}$ is self-administered, whereas pure nicotine at the same dose is not; $n=10$ for CSE, $n=6$ for nicotine; $* 2<0.05$, R (reinf) vs NR (nonreinf). (c) After stable responding at I $5 \mu g / \mathrm{kg} /$ inj, CSE supported responding at the lower $7.5 \mu \mathrm{g} / \mathrm{kg} / \mathrm{inj}$ dose whereas nicotine did not; * $<0.05$ vs nicotine, $n=5$ all groups. (d) CSE and nicotine elicit similar responses under the progressive ratio schedule of reinforcement. There was no significant drug $\times$ day interaction; $n=9$ for CSE, $n=10$ for nicotine.

matched concentration of nicotine did not (Figure 1a and b). In the CSE group, there were significant main effects of day $\left(\mathrm{F}_{14,112}=2.057, p=0.020\right)$ and $\mathrm{R} / \mathrm{NR}\left(\mathrm{F}_{1,112}=9.014\right.$, $p=0.017)$. The post hoc analysis revealed that reinforced responding was significantly greater than non-reinforced on the final days of each reinforcement schedule. There were no significant main effects in the nicotine group.

\section{Dose-Response Study}

For this and all subsequent experiments, a lever press apparatus was used. The level of baseline responding at the $15 \mu \mathrm{g} / \mathrm{kg} /$ infusion dose was similar between the CSE and nicotine groups (14.4 \pm 1.4 in the CSE group and $15.3 \pm 1.6$ in the nicotine group, $p=0.7$ ), as were blood and brain levels of nicotine (see Supplementary Figure 1). In the doseresponse analysis, there were significant main effects of dose $\left(\mathrm{F}_{2,24}=3.650, p=0.041\right)$ and drug $\left(\mathrm{F}_{1,24}=5.281\right.$, $p=0.031)$. The post hoc testing revealed that responding at the $7.5 \mu \mathrm{g} / \mathrm{kg}$ dose was significantly higher for CSE than for nicotine $(p=0.040$; Figure $1 c)$.

\section{PR, Extinction, and Reinstatement}

There were no differences between the CSE and nicotine groups at a $15-\mu \mathrm{g} / \mathrm{kg}$ nicotine-equivalent dose in PR testing (Figure 1d). Following the re-establishment of baseline responding at FR5, all animals began extinction testing. The absolute levels of responding at FR5 before extinction were higher in the CSE group than the nicotine group (12.4 \pm 1.5 in the Nicotine group and $24.9 \pm 3.7$ in the CSE group (mean $\pm \mathrm{SEM}$ ), $p=0.02$ ). Because of this difference, further analyses were based on percent change from baseline responding. On the first day of extinction, animals that responded for nicotine reduced their responding more than those that took CSE $(p=0.045$, Bonferroni corrected unpaired $t$-test). There were no differences in later days (Figure 2a).

In the reinstatement tests, there was a significant main effect of reinstatement type $\left(\mathrm{F}_{3,45}=9.463, p<0.001\right)$ and a significant interaction between reinstatement type and drug $\left(\mathrm{F}_{3,45}=9.463, p=0.043\right)$. Further analysis revealed that reinstatement responding in the nicotine group was significantly higher than the extinction condition in all three reinstatement tests $(p=0.05,0.003$, and 0.021 for the cues, stress, and stress + cues conditions, respectively). The CSE group reinstated significantly to stress $(p=0.003)$ and stress + cues $(p=0.04)$. Reinstatement responding in the stress-alone condition was significantly higher in the CSE group than the nicotine group $(p<0.001$, Bonferroni corrected unpaired $t$-test; Figure $2 \mathrm{~b}$ ).

\section{nAChR Antagonist Study}

Three nAChR antagonists-mecamylamine, varenicline, and AT-1001-were tested for inhibition of nicotine $(15 \mu \mathrm{g} / \mathrm{kg} / \mathrm{inf})$ or CSE $(15 \mu \mathrm{g} / \mathrm{kg} / \mathrm{inf}$ nicotine content) selfadministration (Figure 3). For mecamylamine, there was a significant main effect of dose $\left(\mathrm{F}_{2,34}=9.608, p<0.001\right)$, but no main effects or interactions of drug (Figure $3 \mathrm{a}$ ). Mecamylamine significantly reduced responding for both CSE and nicotine at the $2 \mathrm{mg} / \mathrm{kg}$ dose $(p<0.01$, paired $t$-test). Non-reinforced responding was very low $(<3$ responses for all animals) throughout the experiment and was not affected by drug treatment. 

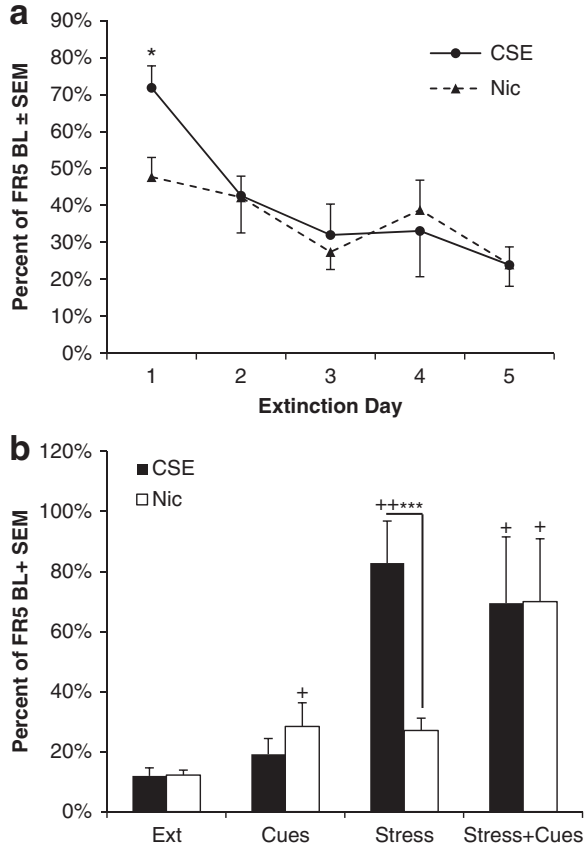

Figure 2 Animals that self-administer cigarette smoke extract (CSE) initially extinguish more slowly and are more susceptible to stress-induced reinstatement. (a) Animals trained to self-administer CSE initially extinguish responding more slowly than those that took nicotine. Data are shown as a percentage of responding for drug on the last day it was available; $* 0.05$ vs nicotine, Bonferroni corrected. (b) Animals that self-administer CSE reinstate more robustly following a stress trigger than nicotine; ${ }^{+} p<0.05$ and ${ }^{+}+0.0$ I vs extinction baseline, ${ }^{*} * * * * 0.00$ I vs nicotine; $n=8$ for CSE, $n=10$ for nicotine.
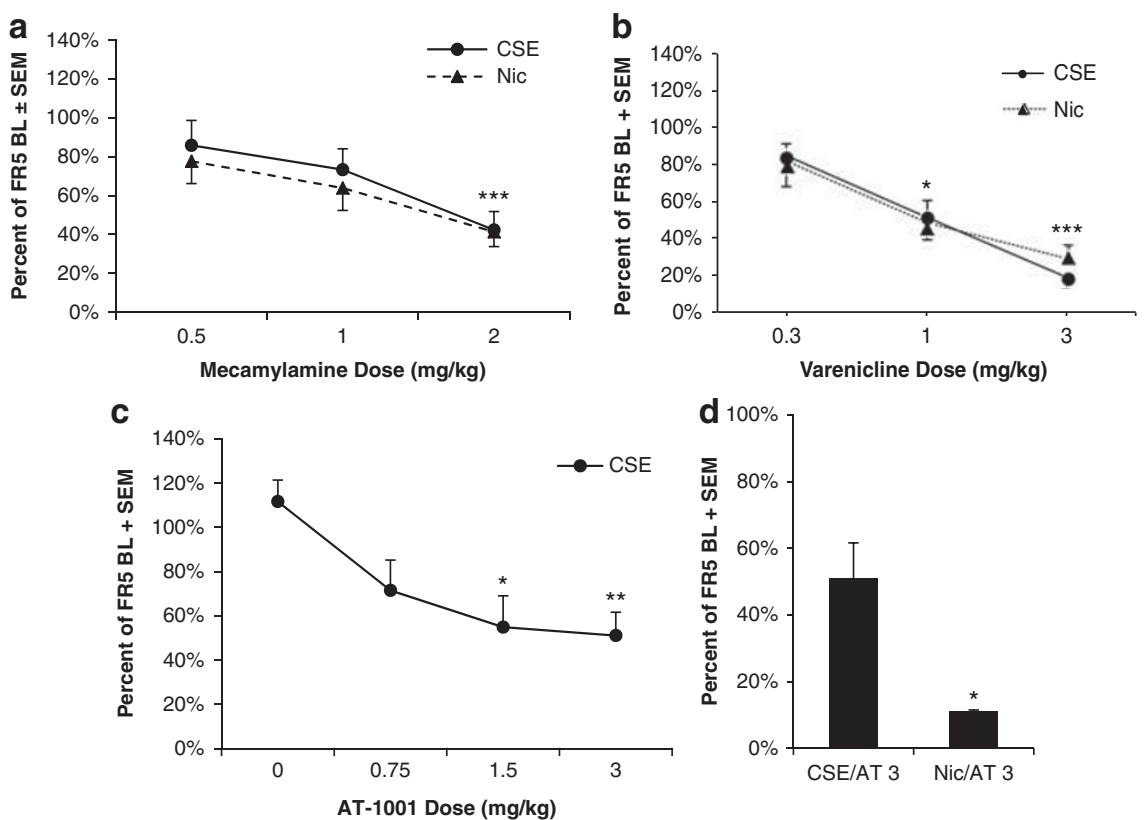

Figure 3 Cigarette smoke extract (CSE) and nicotine respond differently to different nAChR antagonists. (a) CSE and nicotine self-administration were inhibited equally by mecamylamine. ***** $<0.00$ I vs 0.5 dose of mecamylamine, $n=1$ I for CSE, $n=8$ for nicotine. All data are presented as percentage of baseline responding on test day. (b) CSE and nicotine self-administration were inhibited equally by varenicline; $* p<0.05$ I vs 0.3 dose of varenicline, ***** $p<0.0013$ vs $0.3 ; n=6$ for CSE, $n=7$ for nicotine. (c) AT-I00I reduces CSE self-administration in rats in a dose-dependent manner; $* p<0.05$ vs vehicle, ${ }^{*} * x<0.01$ vs vehicle; $n=6$. (d) AT-I00I reduces CSE self-administration in rats to a lesser degree than nicotine; $* p<0.05$ vs CSE group, $n=3$.
For varenicline, there was a significant effect of dose $\left(\mathrm{F}_{2,22}=18.052, p<0.001\right)$, but no significant main effects or interactions of drug (Figure $3 \mathrm{~b})$. Varenicline significantly reduced responding at both 1 and $3 \mathrm{mg} / \mathrm{kg}$ doses $(p<0.05$ and $p<0.001$, respectively, paired $t$-test).

For AT-1001, there was a significant main effect of dose $\left(\mathrm{F}_{3,15}=5.143, p=0.012\right)$ in inhibiting responding for CSE. Both 1.5 and $3 \mathrm{mg} / \mathrm{kg}$ doses significantly reduced CSE selfadministration $(p=0.025$ and $p=0.010$, respectively, paired $t$-test; Figure 3c). In contrast to prior studies with nicotine (Toll et al, 2012), AT-1001 did not fully inhibit responding for CSE at the highest dose. To determine whether this was a significant difference, 3 animals that had completed AT1001 dose-response analysis against CSE were switched to nicotine $(15 \mu \mathrm{g} / \mathrm{kg} /$ infusion $)$. In these animals, AT-1001 $(3 \mathrm{mg} / \mathrm{kg})$ inhibited responding for nicotine significantly more than for CSE ( $p=0.011$; Figure $3 d)$.

\section{nAChR Binding}

There were no significant differences in CSE and nicotine $\mathrm{IC}_{50}$ values for inhibition of radioligand binding to $\alpha 4 \beta 2$, $\alpha 3 \beta 4, \alpha 3 \beta 2$, and $\alpha 7 \mathrm{nAChRs}$ (Table 1).

\section{MAO Activity}

There was no significant main effect of dose in the nicotine group in either the MAO-A or MAO-B assay. All further analyses were performed with CSE only (Figure 4a). In the MAO-A assay, there was a significant main effect of CSE dose $\left(\mathrm{F}_{8,16}=253.996, p<0.001\right)$. The $\mathrm{IC}_{50}$ of CSE (expressed as nicotine concentration) for inhibition of MAO-A was $4.815 \mu \mathrm{M}$ $(95 \% \mathrm{CI} 3.87-5.99 \mu \mathrm{M})$. In the MAO-B assay, there was also a 

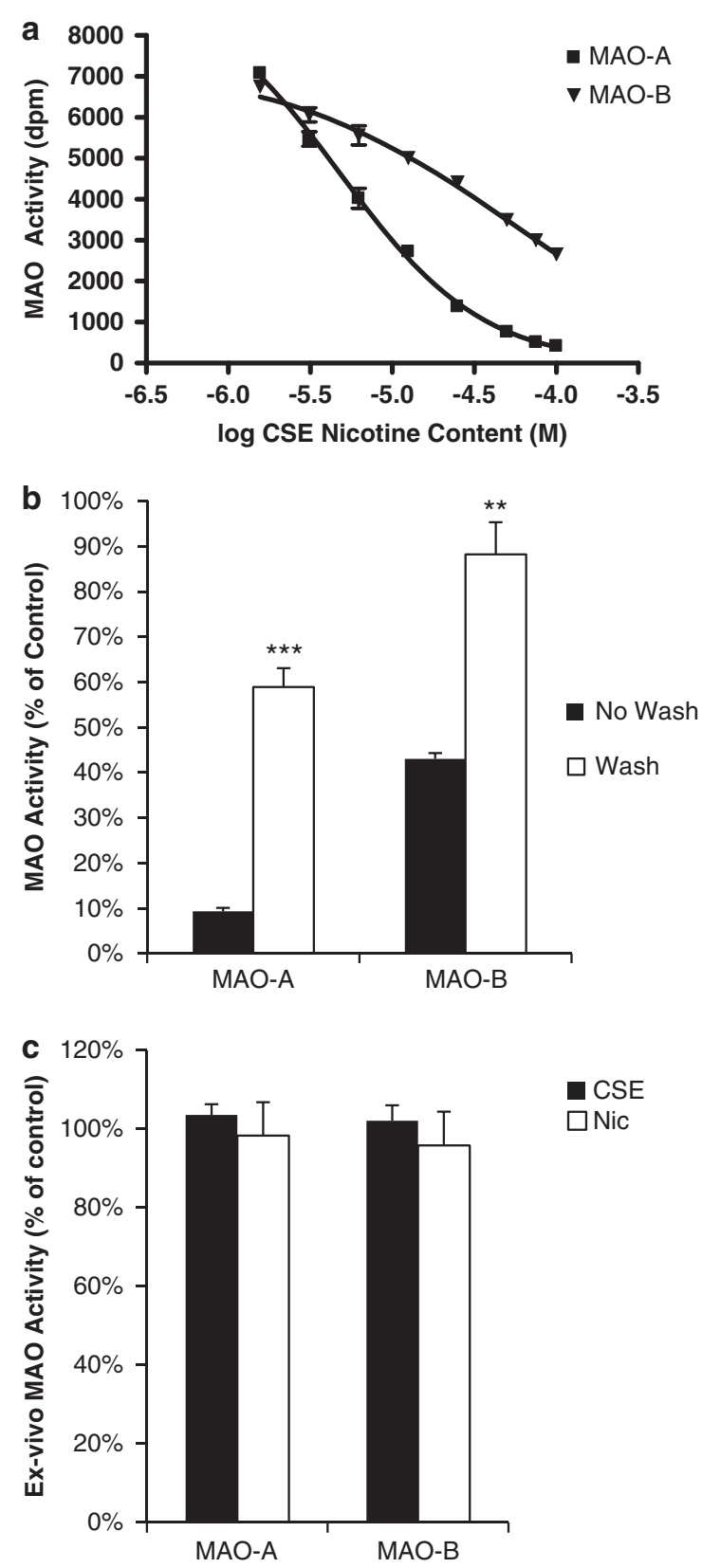

Figure 4 Cigarette smoke extract (CSE) inhibits monoamine oxidase. (a) CSE inhibition of MAO-A and MAO-B. Data are given as percent activity compared with control treatment. All data points were significantly lower than control except the 1.5625 dose for MAO-B. (b) Partial reversibility of MAO inhibition in vitro. 'No wash' is activity after the initial incubation period; 'Wash' is activity following pelleting, removal of supernatant, and resuspending the tissue. Values are CSE activity as a percent of control, *** $<<0.05$, **** $p<0.00$ I vs no wash. (c) Ex vivo MAO activity. Neither MAO-A nor MAO-B activity was inhibited by I h of programmed infusions of either CSE or nicotine; $n=4$ for CSE and nicotine, $n=2$ for saline control.

significant main effect of CSE dose $\left(\mathrm{F}_{8,16}=103.997, p<0.001\right)$. The inhibition of MAO-B by CSE was best fit to a two-site model, with a high-affinity $\mathrm{IC}_{50}$ of $6.06 \mu \mathrm{M}(95 \%$ CI $0.0307-$ $1199 \mu \mathrm{M}, 40 \%$ of inhibition) and a low-affinity $\mathrm{IC}_{50}$ of $72.9 \mu \mathrm{M}$ (95\% CI $0.933-5708 \mu \mathrm{M}, 60 \%$ of inhibition).

MAO inhibition by CSE was partially reversible. Inhibition after washing was significantly lower than before washing in the MAO-A condition ( $p=0.001$, paired $t$-test); however, it did not return to $100 \%$ of control values $(p<0.001$, unpaired $t$-test). MAO-B inhibition was also significantly reduced following the wash $(p=0.005$, paired $t$-test), and was not significantly different from control levels ( $p=0.18$, unpaired $t$-test, Figure $4 \mathrm{~b}$ ).

There was no detectable MAO inhibition following $1 \mathrm{~h}$ of programmed infusions of either CSE or nicotine alone. Both MAO-A and MAO-B activities in the nicotine and CSE groups were equivalent to saline-treated animals (Figure 4c).

\section{DISCUSSION}

This is the first direct comparison of the reinforcing properties of nicotine and CSE. Although CSE is a more potent reinforcer than nicotine, pharmacological studies indicate that $\mathrm{nAChRs}$ play a critical role in mediating the behavioral effects of both drugs. However, there were notable differences in the properties of nicotine and CSE. CSE inhibited MAO activity, as has been observed previously in smokers (Fowler et al,1996a,b). Furthermore, stress-induced reinstatement was significantly higher in animals that had worked for CSE. Given the critical importance of stress as a trigger for reinstatement of smoking in humans, this may indicate that CSE may have more face validity than nicotine for use in preclinical smoking models.

In both the nose poke and lever press self-administration paradigms, animals worked for CSE at doses that yield blood levels close to that of human smokers. The minimum reinforcing CSE doses of 3.75 and $7.5 \mu \mathrm{g}$ nicotine content $/ \mathrm{kg} /$ infusion found in this study are much lower than the standard $30 \mu \mathrm{g} / \mathrm{kg} /$ infusion nicotine dose used in most rat self-administration studies (see, eg, Corrigall and Coen, 1989; Donny et al,1995; Liechti et al, 2007) and are near the amount of nicotine a smoker receives in a single puff of a cigarette (Miller et al, 1977; Rose and Corrigall, 1997). Furthermore, the nicotine blood levels resulting from infusions of CSE at $15 \mu \mathrm{g}$ nicotine content $/ \mathrm{kg} /$ infusion that modeled a selfadministration session were $50 \mathrm{ng} / \mathrm{ml}$, approximately twice that of smokers (Benowitz, 1992). Thus, nicotine levels resulting from lower, threshold doses of CSE would equate to human smoker blood levels. The MAO inhibitor, tranylcypromine, enhances nicotine self-administration at similar doses (Villégier et al, 2007). However, this study is the first to report such a finding using smoke extract. Analysis of nicotine content in plasma and brain tissue revealed no differences between animals that self-administered CSE or nicotine, suggesting differing pharmacokinetic profiles do not account for this difference in potency.

Although CSE did support responding at lower doses than nicotine, the level of responding for nicotine and CSE was equivalent at the $15 \mu \mathrm{g}$ nicotine content $/ \mathrm{kg} /$ infusion dose. In the PR test, which is ideal for separating the reinforcing value of different drugs (Richardson and Roberts, 1996), there was no difference between nicotine and CSE. In contrast, both acetaldehyde (in adolescents) and tranylcypromine (in adults) increased responding far beyond the peak of nicotine alone (Belluzzi et al, 2005; Villégier et al, 2007), similar to effects seen in other labs with nicotine 
Table I Binding Affinities for CSE and Nicotine at nAChRs

\begin{tabular}{|c|c|c|c|c|c|}
\hline nAChR subtype & Region analyzed & CSE $K_{i}$ & CSE 95\% Cl & $\mathrm{Nic}_{\mathbf{i}}$ & $\mathrm{Nic} 95 \% \mathrm{Cl}$ \\
\hline$\alpha 4 \beta 2$ & VPM/VPL thalamus & $10.34 \mathrm{nM}$ & $7.7-13.8 \mathrm{nM}$ & I6.29 nM & I I.2-23.8 nM \\
\hline$\alpha 3 \beta 4$ & Medial habenula & $1.112 \mu \mathrm{M}$ & $0.75-1.66 \mu \mathrm{M}$ & $1.285 \mu \mathrm{M}$ & $0.85-1.86 \mu \mathrm{M}$ \\
\hline$\alpha 3 \beta 2$ & Superior colliculus & $0.0809 \mu \mathrm{M}$ & $0.024-0.272 \mu \mathrm{M}$ & $0.172 \mu \mathrm{M}$ & $0.032-0.921 \mu \mathrm{M}$ \\
\hline$\alpha 7$ & Dentate gyrus & $32.69 \mu \mathrm{M}$ & 19.6-54.5 $\mu \mathrm{M}$ & $38.05 \mu \mathrm{M}$ & $21.42-67.62 \mu \mathrm{M}$ \\
\hline
\end{tabular}

alkaloids (Clemens et al, 2009). However, smokers typically titrate their cigarette intake and will maintain a steady level of use for many years (Park et al, 2012). Our results are therefore consistent with human data, in that CSE is quite potent but not as reinforcing as other drugs of abuse.

Mecamylamine and varenicline reduced responding for both CSE and nicotine to the same degree. The observed reduction in responding is similar to that previously reported for nicotine self-administration (eg, Donny et al, 1995; Rollema et al, 2007). These data suggest that nAChR activation is required for CSE reinforcing effects, a concept that is supported by our ligand binding data that showed CSE and nicotine to have equal affinity for all tested $\mathrm{nAChR}$ subtypes. Surprisingly, given these data, AT-1001, an $\alpha 3 \beta 4$ nAChR antagonist that we have previously shown to potently block nicotine self-administration (Toll et al, 2012), was less effective in blocking responding for CSE than for nicotine alone. We have previously shown that AT1001 does not impact responding for food at the doses used in the present study (Toll et al, 2012). Mecamylamine and varenicline have similarly been shown to have no impact on food responding at doses we found to significantly inhibit nicotine and CSE self-administration (Levin et al, 2000; Ginsburg and Lamb, 2013). Thus, the effects observed in this study are not likely because of a general decrease in activity. These findings suggest that different $\mathrm{nAChR}$ mechanisms underlie self-administration of CSE and nicotine.

Responding for CSE was more persistent during the first day of extinction than that of nicotine. Furthermore, there were significant differences in patterns of reinstatement of CSE- and nicotine-seeking behaviors. Reinstatement to nicotine-seeking behavior was similar to that reported previously, with additive reinstatement to cues and to a pharmacological stressor, yohimbine (Feltenstein et al, 2012). In contrast, animals that had self-administered CSE reinstated more robustly to stress alone, with no additional effect of cue exposure. Prior work has identified separate neural mechanisms underlying cue- and stress-induced reinstatement. Whereas cue-induced reinstatement is predominantly mediated by dopaminergic and glutamatergic pathways, stress-induced reinstatement involves corticotropin-releasing factor and norepinephrine (Feltenstein and See, 2008; Kalivas and McFarland, 2003). Differential effects of CSE and nicotine on these pathways may reflect their differing potencies as inhibitors of MAO-A and - $\mathrm{B}$, the important regulators of catecholamine function (Bortolato et al, 2008).

In contrast to the lack of effect of nicotine, CSE inhibited both MAO-A and B in vitro. There are several known MAO inhibitors in tobacco smoke, including 2-napthylamin
(Hauptmann and Shih, 2001), harman, and norharmane (Herraiz and Chaparro, 2005), yet these are all reversible. However, the inhibition produced by CSE was only partially reversible, suggesting that there may indeed be an irreversible MAO inhibitor in CSE. Consistent with our present findings, extracts of unburned tobacco or smokeless tobacco exhibit very little MAO inhibition activity (Alford et al, 2006; Castagnoli et al, 2002), whereas smoke extract potently inhibits MAO (Castagnoli et al, 2002; Lewis et al, 2012) with both irreversible and reversible components (Castagnoli et al, 2002). Although we found irreversible inhibition of MAO-A activity in vitro, irreversible inhibition was not observed in washed brain membranes following in vivo administration of CSE. Brain nicotine levels in CSE-treated animals were $\sim 1.3 \mu \mathrm{M}$, close to the lowest tested CSE concentration in the MAO assay $(1.56 \mu \mathrm{M})$, that induced $6 \pm 2 \%$ and $4 \pm 3 \%$ reductions in MAO-A and $-\mathrm{B}$ activity, respectively. However, because the nonnicotine constituents of the CSE may penetrate the brain differently than nicotine, care must be taken when extrapolating the in vitro results to the behavioral studies. Our work shows that CSE can inhibit $\mathrm{MAO}$ across a range of doses at which nicotine has no effect; however, further work is required to determine if CSE is having such an effect in vivo. Thus, any irreversible MAO inhibitor in the CSE may either be present at a very low concentration in vivo or unable to penetrate the brain.

Our group has shown that treating animals with tranylcypromine, an irreversible MAO inhibitor, enhances nicotine self-administration (Villégier et al, 2007). However, inhibiting the enzyme alone was insufficient to produce this effect (Villégier et al, 2007). Acute monoamine release induced by tranylcypromine plays a critical role in enhancement of self-administration behavior, along with MAO inhibition (Villégier et al, 2007). Norharmane, a reversible MAO inhibitor found in tobacco smoke, has similar monoamine releasing properties, suggesting that similar compounds may be present in CSE. Future studies to determine whether CSE can directly induce monoamine release would help to clarify the mechanisms underlying its behavioral effects.

There are several limitations to the current work that warrant further investigation. The primary challenge in interpreting these results is that the exact composition of CSE is unknown. Furthermore, the nonaqueous components of cigarette smoke are not included. In addition, there is a possibility that the composition of CSE was not consistent between batches, either because of variations in the cigarettes themselves or minor inconsistencies in the preparation. However, the effects on self-administration of CSE compared with nicotine remained consistent across 
multiple tests, suggesting that any variations were not behaviorally relevant. Our results therefore provide proof of concept that CSE is more reinforcing than pure nicotine and pave the way for future studies to fully characterize the compounds responsible for these behavioral effects.

CSE self-administration represents a novel way to include the nonnicotine effects of tobacco smoke in a preclinical model. CSE self-administration has better face validity as a model of smoking than pure nicotine by including many tobacco constituents. Furthermore, CSE increased potency and enhanced stress-induced reinstatement, a potent trigger for relapse in smokers (Cummings et al, 1985). Furthermore, we have shown that one potential therapy for tobacco dependence behaves differently in this model than in nicotine self-administration. Screening smoking cessation therapies in the CSE self-administration model thus may have improved predictive validity and be an important tool in the pursuit of better treatments.

\section{FUNDING AND DISCLOSURE}

The authors declare no conflict of interest.

\section{ACKNOWLEDGEMENTS}

Funding was provided by the UC Tobacco Related Diseases Research Program 18XT-0085 (to FML) and the Pharmaceutical Research and Manufacturers of America Foundation (PhRMA) 47930 (to MRC).

\section{REFERENCES}

Alford GS, Szebeni K, Klimek V, Piletz JE, Orr S, Ordway GA (2006). Effect of smokeless tobacco extract on catecholamine metabolic enzymes in rat brain: "dippers" are getting only half of the bang. Addict Behav 31: 1503-1509.

Bates C, McNeill A, Jarvis M, Gray N (1999). The future of tobacco product regulation and labelling in Europe: implications for the forthcoming European Union directive. Tob Control 8: 225-235.

Belluzzi JD, Wang R, Leslie FM (2005). Acetaldehyde enhances acquisition of nicotine self-administration in adolescent rats. Neuropsychopharmacology 30: 705-712.

Benowitz NL (1992). Cigarette smoking and nicotine addiction. Med Clin North Am 76: 415-437.

Bernhard D, Huck CW, Jakschitz T, Pfister G, Henderson B, Bonn GK et al (2004). Development and evaluation of an in vitro model for the analysis of cigarette smoke effects on cultured cells and tissues. J Pharmacol Toxicol Methods 50: 45-51.

Bortolato M, Chen K, Shih JC (2008). Monoamine oxidase inactivation: from pathophysiology to therapeutics. Adv Drug Deliv Rev 60: 1527-1533.

Brennan KA, Putt F, Truman P (2013). Nicotine-, tobacco particulate matter- and methamphetamine-produced locomotor sensitisation in rats. Psychopharmacology 228: 659-672.

Brody AL, London ED, Olmstead RE, Allen-Martinez Z, Shulenberger S, Costello MR et al (2010). Smoking-induced change in intrasynaptic dopamine concentration: effect of treatment for Tobacco Dependence. Psychiatry Res 183: 218-224.

Castagnoli K, Steyn SJ, Magnin G, Van Der Schyf CJ, Fourie I, Khalil A et al (2002). Studies on the interactions of tobacco leaf and tobacco smoke constituents and monoamine oxidase. Neurotox Res 4: 151-160.

Centers for Disease Control and Prevention (US) 2010. How tobacco smoke causes disease: The biology and behavioral basis for smoking-attributable disease. A Report of the Surgeon General. Atlanta, GA.

CDC (2008). Cigarette smoking among adults-United States, 2007. MMWR 56: 1157-1161.

Clemens KJ, Caille S, Stinus L, Cador M (2009). The addition of five minor tobacco alkaloids increases nicotine-induced hyperactivity, sensitization and intravenous self-administration in rats. Int J Neuropsychopharmacol 12: 1355-1366.

Coe JW, Brooks PR, Vetelino MG, Wirtz MC, Arnold EP, Huang J et al (2005). Varenicline: an alpha4beta2 nicotinic receptor partial agonist for smoking cessation. $J$ Med Chem 48: 3474-3477.

Corrigall WA, Coen KM (1989). Nicotine maintains robust selfadministration in rats on a limited-access schedule. Psychopharmacology (Berl) 99: 473-478.

Cummings KM, Jaen CR, Giovino G (1985). Circumstances surrounding relapse in a group of recent exsmokers. Prev Med 14: 195-202.

Dar R, Frenk H (2004). Do smokers self-administer pure nicotine? A review of the evidence. Psychopharmacology (Berl) 173: $18-26$.

Domino EF, Ni L, Domino JS, Yang W, Evans C, Wang $\mathrm{H}$ et al (2013). Denicotinized versus average nicotine tobacco cigarette smoking differentially releases striatal dopamine. Nicotine Tob Res 15: 11-21.

Donny EC, Caggiula AR, Knopf S, Brown C (1995). Nicotine selfadministration in rats. Psychopharmacology (Berl) 122: 390-394.

Donny EC, Caggiula AR, Mielke MM, Booth S, Gharib MA, Hoffman A et al (1999). Nicotine self-administration in rats on a progressive ratio schedule of reinforcement. Psychopharmacology (Berl) 147: 135-142.

Feltenstein MW, Ghee SM, See RE (2012). Nicotine self-administration and reinstatement of nicotine-seeking in male and female rats. Drug Alcohol Depend 121: 240-246.

Feltenstein MW, See RE (2008). The neurocircuitry of addiction: an overview. Br J Pharmacol 154: 261-274.

Fowler JS, Volkow ND, Wang GJ, Pappas N, Logan J, MacGregor R et al (1996a). Inhibition of monoamine oxidase B in the brains of smokers. Nature 379: 733-736.

Fowler JS, Volkow ND, Wang GJ, Pappas N, Logan J, Shea C et al (1996b). Brain monoamine oxidase A inhibition in cigarette smokers. Proc Natl Acad Sci USA 93: 14065-14069.

Ginsburg BC, Lamb RJ (2013). Effects of varenicline on ethanoland food-maintained responding in a concurrent access procedure. Alcohol Clin Exp Res 37: 1228-1233.

Guillem K, Vouillac C, Azar MR, Parsons LH, Koob GF, Cador M et al (2005). Monoamine oxidase inhibition dramatically increases the motivation to self-administer nicotine in rats. J Neurosci 25: 8593-8600.

Harris AC, Stepanov I, Pentel PR, Lesage MG (2011). Delivery of nicotine in an extract of a smokeless tobacco product reduces its reinforcement-attenuating and discriminative stimulus effects in rats. Psychopharmacology (Berl) 220: 565-576.

Hauptmann N, Shih JC (2001). 2-Naphthylamine, a compound found in cigarette smoke, decreases both monoamine oxidase A and B catalytic activity. Life Sci 68: 1231-1241.

Herraiz T, Chaparro C (2005). Human monoamine oxidase is inhibited by tobacco smoke: beta-carboline alkaloids act as potent and reversible inhibitors. Biochem Biophys Res Commun 326: 378-386.

Jorenby DE, Hays JT, Rigotti NA, Azoulay S, Watsky EJ, Williams $\mathrm{KE}$ et al (2006). Efficacy of varenicline, an alpha4beta2 nicotinic acetylcholine receptor partial agonist, vs placebo or sustainedrelease bupropion for smoking cessation: a randomized controlled trial. JAMA 296: 56-63.

Kalivas PW, McFarland K (2003). Brain circuitry and the reinstatement of cocaine-seeking behavior. Psychopharmacology (Berl) 168: 44-56. 
Khalki H, Navailles S, Piron CL, De DP (2013). A tobacco extract containing alkaloids induces distinct effects compared to pure nicotine on dopamine release in the rat. Neurosci Lett 544: 85-88.

King A, McNamara P, Conrad M, Cao D (2009). Alcohol-induced increases in smoking behavior for nicotinized and denicotinized cigarettes in men and women. Psychopharmacology (Berl) 207: 107-117.

Levin ED, Mead T, Rezvani AH, Rose JE, Gallivan C, Gross R. (2000). The nicotinic antagonist mecamylamine preferentially inhibits cocaine vs. food self-administration in rats. Physiol Behav 71: 565-570.

Lewis AJ, Truman P, Hosking MR, Miller JH (2012). Monoamine oxidase inhibitory activity in tobacco smoke varies with tobacco type. Tob Control 21: 39-43.

Liechti ME, Lhuillier L, Kaupmann K, Markou A (2007). Metabotropic glutamate $2 / 3$ receptors in the ventral tegmental area and the nucleus accumbens shell are involved in behaviors relating to nicotine dependence. J Neurosci 27: 9077-9085.

Liu H, Zhou Y, Boggs SE, Belinsky SA, Liu J (2007). Cigarette smoke induces demethylation of prometastatic oncogene synuclein-gamma in lung cancer cells by downregulation of DNMT3B. Oncogene 26: 5900-5910.

Marti F, Arib O, Morel C, Dufresne V, Maskos U, Corringer PJ et al (2011). Smoke extracts and nicotine, but not tobacco extracts, potentiate firing and burst activity of ventral tegmental area dopaminergic neurons in mice. Neuropsychopharmacology 36: 2244-2257.

Miller RP, Rotenberg KS, Adir J (1977). Effect of dose on the pharmacokinetics of intravenous nicotine in the rat. Drug Metab Dispos 5: 436-443.

Oreland L, Fowler CJ, Schalling D (1981). Low platelet monoamine oxidase activity in cigarette smokers. Life Sci 29: 2511-2518.

Ospina JA, Broide RS, Acevedo D, Robertson RT, Leslie FM (1998). Calcium regulation of agonist binding to alpha7-type nicotinic acetylcholine receptors in adult and fetal rat hippocampus. J Neurochem 70: 1061-1068.

Park S, Lee JY, Song TM, Cho SI (2012). Age-associated changes in nicotine dependence. Public Health 126: 482-489.
Perry DC, Xiao Y, Nguyen HN, Musachio JL, Davila-Garcia MI, Kellar KJ (2002). Measuring nicotinic receptors with characteristics of alpha4beta2, alpha3beta2 and alpha3beta4 subtypes in rat tissues by autoradiography. J Neurochem 82: 468-481.

Reus VI, Smith BJ (2008). Multimodal techniques for smoking cessation: a review of their efficacy and utilisation and clinical practice guidelines. Int J Clin Pract 62: 1753-1768.

Richardson NR, Roberts DC (1996). Progressive ratio schedules in drug self-administration studies in rats: a method to evaluate reinforcing efficacy. J Neurosci Methods 66: 1-11.

Rollema H, Chambers LK, Coe JW, Glowa J, Hurst RS, Lebel LA et al (2007). Pharmacological profile of the alpha4beta2 nicotinic acetylcholine receptor partial agonist varenicline, an effective smoking cessation aid. Neuropharmacology 52: 985-994.

Rose JE, Corrigall WA (1997). Nicotine self-administration in animals and humans: similarities and differences. Psychopharmacology (Berl) 130: 28-40.

See RE, Waters RP. (2010). Pharmacologically-induced stress: a cross-species probe for translational research in drug addiction and relapse. Am J Transl Res. 22 3: 81-89.

Seeman JI, Dixon M, Haussmann HJ (2002). Acetaldehyde in mainstream tobacco smoke: formation and occurrence in smoke and bioavailability in the smoker. Chem Res Toxicol 15: 1331-1350.

Sydnor KL, Allen C, Higgins B (1972). Effect of an aqueous extract of cigarette-smoke condensate on benzo(a)pyrene-induced sarcoma and body weight in the rat. J Natl Cancer Inst 48: 893-909.

Toll L, Zaveri NT, Polgar WE, Jiang F, Khroyan TV, Zhou W et al (2012). AT-1001: a high affinity and selective alpha3beta4 nicotinic acetylcholine receptor antagonist blocks nicotine self-administration in rats. Neuropsychopharmacology 37: 1367-1376.

Touiki K, Rat P, Molimard R, Chait A, de Beaurepaire R (2007). Effects of tobacco and cigarette smoke extracts on serotonergic raphe neurons in the rat. Neuroreport 18: 925-929.

Villégier AS, Lotfipour S, McQuown SC, Belluzzi JD, Leslie FM (2007). Tranylcypromine enhancement of nicotine self-administration. Neuropharmacology 52: 1415-1425.

Supplementary Information accompanies the paper on the Neuropsychopharmacology website (http://www.nature.com/npp) 